\title{
CLINICAL PROFILE OF HOSPITALIZED CHILDREN WITH FEBRILE SEIZURES
}

\section{Paediatrics \\ Dr. Javeri Aarti Harish* \\ Post Graduate Student, Department of Paediatrics, Sree Balaji Medical College and Hospital. *Corresponding Author \\ Professor and Head of the Department, Department of Paediatrics, Sree Balaji Medical College and Hospital. \\ Dr. Sundari}

\section{ABSTRACT}

Objective: The objectives of this study were to evaluate the clinical profile, investigations, course in hospital and outcome of children admitted with febrile seizures.

Methods: 70 children with febrile seizures were taken as study subjects. The study was conducted over six months, from June 2018 to November 2018. Clinical, laboratory, EEG, and neuroimaging data were evaluated.

Results: The children's ages ranged between 7-70 months (mean 20, SD 14), and 58.5\% were males. Majority of the hospitalized children (60 out of 70 ) had complex febrile seizures (55\%), were dull looking (24.5\%), suffered from status (17.5\%), or positive meningeal irritation signs (4\%). Electrolyte abnormalities were uncommon (10\%), however, complete blood count was found to be abnormal in $45 \%$, which increased the likelihood of receiving intravenous antibiotics $(\mathrm{p}=0.01)$. Lumbar puncture was performed in those who demonstrated signs of meningeal irritation or those who were younger than 2 years of age. MRI Brain was performed in $15.71 \%$ and EEG in $35.71 \%$. Obtaining an EEG was less likely if the seizures were typical ( $13 \%$ versus $50 \%$ in atypical, $\mathrm{p}=0.002)$. Duration of hospitalization ranged between $1-14$ days (mean $4.7, \mathrm{SD} 3.2)$, and only one child had meningitis, which was predicted clinically.

Conclusions: Those children who were admitted frequently had complex febrile seizures, status epilepticus, or were ill looking. Simple febrile seizures are generally investigated selectively. However, it was observed that the yield of investigations remains low and does not justify extensive work-up or prolonged hospitalization.

\section{KEYWORDS}

\section{INTRODUCTION:}

Febrile seizures is the most common seizure disorder in children younger than 5 years of age. Most febrile seizures are brief, do not require any specific treatment or workup, and have good prognosis. ${ }^{[1]}$ Elective admission on a routine basis increases the tendency to perform unnecessary investigations and therefore should be discouraged. Generally those children are admitted who suffer from recurrent or long atypical seizures, with an underlying serious infection, or where parental anxiety and other social factors play a role ${ }^{[2]}$. Inspite of a clear understanding of this benign epilepsy syndrome, a wide variation in management exists, especially when the child is admitted to hospital ${ }^{[3]}$. Sweeney et al ${ }^{[4]}$ concluded that a wide range of investigations were performed in each hospital. Blood culture and sensitivity were performed in 6-56\% of children and complete blood count $(\mathrm{CBC})$ in $8-70 \%$. The yield of such investigations remains low, making these investigations unnecessary at times. $23-78 \%$ of children were prescribed antibiotics.

In one study, the risk of occult bacteremia was merely $2.1 \%$, which is similar to those with an acute fever illness alone ${ }^{[5]}$. Other studies wherein blood and urine cultures were performed in all admitted cases of febrile seizures demonstrated positive results in only $4.3 \%$ (blood) and $2.6 \%$ (urine) of the children ${ }^{[6]}$. In addition, the rates of serious bacterial illness were low and consistent with those published previously that evaluated children with fever without seizures ${ }^{[7}$ Electrolyte abnormalities are also extremely uncommon in infants and children with simple febrile seizures as compared to those with complex febrile seizures ${ }^{[8]}$. The yield of EEG is also low in neurologically normal children with febrile seizures even if the seizure was atypical ${ }^{[9,10]}$. This led to the conclusion that the routine practice of obtaining EEG in neurologically normal children with simple febrile seizures is not justified. Therefore, the objectives of this study were to evaluate the clinical profile, investigations, course in hospital and outcome of children admitted with febrile seizures.

\section{METHODS AND MATERIALS:}

The study was performed at Sree Balaji Medical College and Hospital, Chennai over a period of six months from June 2018 to November 2018. It was a cross-sectional study involving 70 patients. Children who were admitted with febrile seizures were taken as study subjects. Informed consent was obtained. A structured proforma was designed and used to gather clinical, laboratory, EEG, and neuroimaging data. A febrile seizure was defined as a seizure accompanied by fever without central nervous system infection, occurring in children from 6 months to 5 years of age. The febrile seizure was considered atypical (complex) if it were focal or prolonged ( $>15$ minutes), more than one episode occurring over 24 hours ${ }^{[1]}$

\section{RESULTS:}

Seventy children with febrile seizures were included. There were 41 $(58.5 \%)$ males and $29(41.5 \%)$ females. The children's ages ranged between 7-70 months (mean 20, SD 14). The duration of hospitalization ranged between 1-14 days (mean 4.7, SD 3.2). Fifteen children $(21.42 \%)$ had past history of a febrile seizure and twenty three $(32.85 \%)$ had positive family history of febrile seizures. Majority of the hospitalized children (60 out of 70) had complex febrile seizures $(55 \%)$, were dull looking $(24.5 \%)$, suffered from status $(17.5 \%)$, or positive meningeal irritation signs $(4 \%)$. The source of the febrile illness was evident in $65 \%$, mostly resulting from upper respiratory tract infection. Investigations performed most commonly included $\mathrm{CBC}$ and serum electrolytes. Electrolyte abnormalities were uncommon and minor in $10 \%$, however, the $\mathrm{CBC}$ showed abnormalities suggestive of an infection in $45 \%$ cases. An abnormal $\mathrm{CBC}$ increased the likelihood of receiving intravenous (IV) antibiotics during the hospitalization $(\mathrm{p}=0.01)$, however, only 3 children had a positive blood culture. Lumbar puncture was performed in those who demonstrated signs of meningeal irritation or those who were younger than 2 years of age $(78.57 \%)$. Only one child had a positive cerebrospinal fluid (CSF) culture confirming meningitis. She presented with febrile status, was toxic looking, and had positive meningeal irritation signs. Ten (14.28\%) children had mild nonspecific CSF abnormalities. An EEG was performed on 25 (35.71\%) children, which were normal in 16 or showed minor nonspecific changes in 6 . Epileptiform discharges were noted in 3 EEGs. Obtaining an EEG was less likely in case of simple febrile seizures $(13 \%$ versus $50 \%$ in atypical, $\mathrm{p}=0.002$ ). However, EEG abnormality did not correlate with the seizure type. MRI Brain was performed in 11 (15.71\%) children and were normal in 9 cases. Two abnormal scans showed mild brain edema in one case and (?) tuberculoma in the second. With regards to the course in hospital, including management, 62 patients $(88.57 \%)$ received intravenous fluids (IVF). Totally 51 (72.85\%) children received IV antibiotics during hospitalization. An abnormal CBC increased the likelihood of receiving IV antibiotics during the hospitalization $(\mathrm{p}=0.01)$. Twenty four $(34.28 \%)$ children received an antiepileptic drug (AED) in the ER, mostly for ongoing seizures or status epilepticus $(\mathrm{p}=0.02)$. However, only $10(14.28 \%)$ continued to receive an AED during the hospitalization. These children were more likely to have complex febrile seizures $(\mathrm{p}=0.03)$ or status epilepticus at presentation $(\mathrm{p}=0.04)$. 


\section{Table 1: Age Distribution of Patients}

\begin{tabular}{|l|l|}
\hline $6-12$ months & 27 cases \\
\hline $12-24$ months & 28 cases \\
\hline $2-5$ years & 13 cases \\
\hline More than 5 years & 2 cases \\
\hline
\end{tabular}

Table 2: Duration of hospitalization

\begin{tabular}{|l|l|}
\hline $1-2$ days & 20 cases \\
\hline $3-5$ days & 31 cases \\
\hline $6-10$ days & 13 cases \\
\hline More than 10 days & 6 cases \\
\hline
\end{tabular}

\section{DISCUSSION:}

The study results suggest that simple febrile seizure cases are selectively admitted. Most admitted children had complex febrile seizures, were ill looking, had febrile status epilepticus, or positive meningeal irritation signs. These features were more common in the study sample of this study when compared to earlier studies from other developing countries. Deng et $\mathrm{al}^{[13]}$ found $33 \%$ of their admitted febrile seizure children to have atypical features. Though the sample size was small, it was representative of admitted children with febrile seizures to the institution where the study was conducted. Almost $60 \%$ of our patients were males. The higher incidence in males has been earlier documented with a male to female ratio of approximately 1.5-2:1.7. ${ }^{[13]}$ Overall, around $75 \%$ had LP in contrast to an earlier study documenting that $96 \%$ of admitted children with febrile seizure had undergone LP. ${ }^{[14]}$ This finding thus reflects the trend of more selective treatment. The yield of LP remains low only one child demonstrated a positive CSF culture. Other investigators also concluded that excluding meningitis and encephalitis through careful history, examination, observation, and occasionally LP in children less than 2 years of age is all that is needed. ${ }^{[15]} \mathrm{A} \mathrm{CBC}$ and serum electrolytes were performed on all children. Both were not clinically very helpful, however, an abnormally high white blood cell (WBC) count resulted in increased exposure to IV antibiotics unnecessarily (the high WBC count is most likely seizure related). Other investigators also found a low yield of such investigations. ${ }^{[4,7,8,14]}$ An EEG was performed selectively on one third of our children, mostly those with atypical febrile seizures, which did not yield any significant abnormality in most cases. MRI Brain was performed in $11(15.71 \%)$ children and were normal in 9 cases. Two abnormal scans showed mild brain edema in one case and (?) tuberculoma in the second, however, no focal lesions were identified. The current American Academy of Pediatrics (AAP) recommendations recommend that neuroimaging must not be performed routinely in febrile seizures. ${ }^{[3]}$ Regarding the management, the use of IVF was decided upon clinically and was mostly reserved for dull looking and toxic children. However, around $70 \%$ received IV antibiotics during hospitalization, namely, more or less routinely, which should be discouraged given the low risk of bacteremia and meningitis in these children. Alternately, AEDs were used judiciously in the ER and during hospitalization, which is consistent with the latest AAP recommendations, which state that that AEDs should not be used routinely to prevent simple febrile seizure recurrence. ${ }^{[16]}$

\section{CONCLUSION:}

It was observed that children with simple febrile seizures are often selective admitted. The cases admitted frequently had a good reason for admission. However, the yield of investigations remains low and does not justify extensive work-up or prolonged hospitalization.

\section{REFERENCES}

1. Warden CR, Zibulewsky J, Mace S, Gold C, Gausche-Hill M. Evaluation and Warden CR, Zibulewsky J, Mace S, Gold C, Gausche-Hill M. Evaluation and
management of febrile seizures in the out of hospital and emergency department settings. Ann Emerg Med 2003; 41:215-222.

2. Surpure JS. Febrile convulsions. What happens to the infant admitted to the hospital. Clin Pediatr 1980; 19:361-362.

3. Practice parameter: the neurodiagnostic evaluation of the child with a first simple febrile seizure. American Academy of Pediatrics. Provisional Committee on Quality Improvement, Subcommittee on Febrile Seizures. Pediatrics 1996; 97: 769-772; discussion 773-775.

4. Sweeney A, Gibbs J, Monteil F, Appleton R, Choonara I. The management of febrile seizures in the Mersey region. Dev Med Child Neurol 1996; 38: 578-584.

5. Shah SS, Alpern ER, Zwerling L, Reid JR, McGowan KL, Bell LM. Low risk of bacteremia in children with febrile seizures. Arch Pediatr Adolesc Med 2002; 156: 469472

6. McIntyre PB, Gray SV, Vance JC. Unsuspected bacterial infections in febrile convulsions. Med JAust 1990; 152: 183-186.

Trainor JL, Hampers LC, Krug SE, Listernick R. Children with first time simple febrile seizures are at low risk of serious bacterial illness. Acad Emerg Med 2001;

8: 781-787. 8. Scarfone RJ, Pond K, Thompson K, Fall I. Utility of laboratory testing for infants with seizures. Pediatr Emerg Care 2000; 16: 309-312.

9. Maytal J, Steele R, Eviatar L, Novak G. The value of early postictal EEG in children with complex febrile seizures. Epilepsia 2000;41:219-221.

10. Jan MMS. Assessment of the Utility of Pediatric Electroencephalography. Seizure 2002;
11:99-103.

11. Nelson KB, Ellenberg JH. Predictors of epilepsy in children who have experienced febrile seizures. NEngl J Med 1976;295:1029-1033.

12. Dean AG, Dean JA, Burton A, Dicker R. Epi Info: A general-purpose microcomputer program for public health information systems. Am J Prev Med 1991; 7: 178-182.

13. Deng CT, Zulkifli HI, Azizi BH. Febrile seizures in Malaysian children: epidemiology and clinical features. Med J Malaysia 1994; 49:341-347.

14. Rutter N, Smales OR. Role of routine investigations in children presenting with thei first febrile convulsion. Arch Dis Child 1977; 52: 188-191.

15. Joffe A, McCormick M, DeAngelis C. Which children with febrile seizures need lumbar puncture. Adecision analysis approach. Am J Dis Child 1983; 137: 1153-1156.

16. Baumann RJ, Duffner PK. Treatment of children with simple febrile seizures: the AAP practice parameter. American Academy of Pediatrics. Pediatr Neurol 2000; 23: 11-17. 